
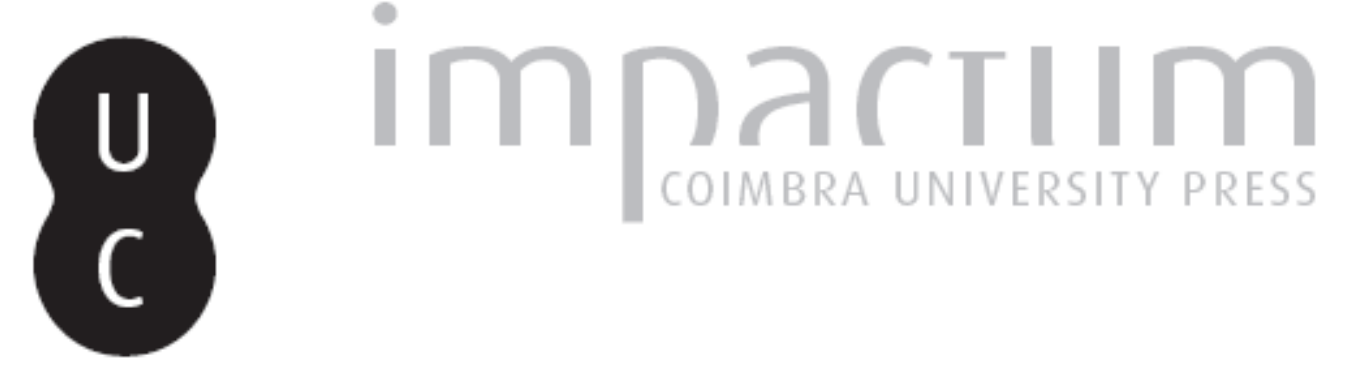

\title{
[Recensão a] MARTINS, Rui Cunha - O Método da Fronteira. Radiografia Histórica de um Dispositivo Contemporâneo (Matrizes Ibéricas e Americanas )
}

\author{
Autor(es): $\quad$ Barros, Victor
}

Publicado por: Imprensa da Universidade de Coimbra

URL

persistente:

URI:http://hdl.handle.net/10316.2/36459

DOI:

DOI:http://dx.doi.org/10.14195/1647-8622_10_27

Accessed : $\quad$ 26-Apr-2023 08:07:24

A navegação consulta e descarregamento dos títulos inseridos nas Bibliotecas Digitais UC Digitalis, UC Pombalina e UC Impactum, pressupõem a aceitação plena e sem reservas dos Termos e Condições de Uso destas Bibliotecas Digitais, disponíveis em https://digitalis.uc.pt/pt-pt/termos.

Conforme exposto nos referidos Termos e Condições de Uso, o descarregamento de títulos de acesso restrito requer uma licença válida de autorização devendo o utilizador aceder ao(s) documento(s) a partir de um endereço de IP da instituição detentora da supramencionada licença.

Ao utilizador é apenas permitido o descarregamento para uso pessoal, pelo que o emprego do(s) título(s) descarregado(s) para outro fim, designadamente comercial, carece de autorização do respetivo autor ou editor da obra.

Na medida em que todas as obras da UC Digitalis se encontram protegidas pelo Código do Direito de Autor e Direitos Conexos e demais legislação aplicável, toda a cópia, parcial ou total, deste documento, nos casos em que é legalmente admitida, deverá conter ou fazer-se acompanhar por este aviso.

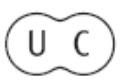




\section{crises do século}

\section{ESTUD OSD OSÉCULO}

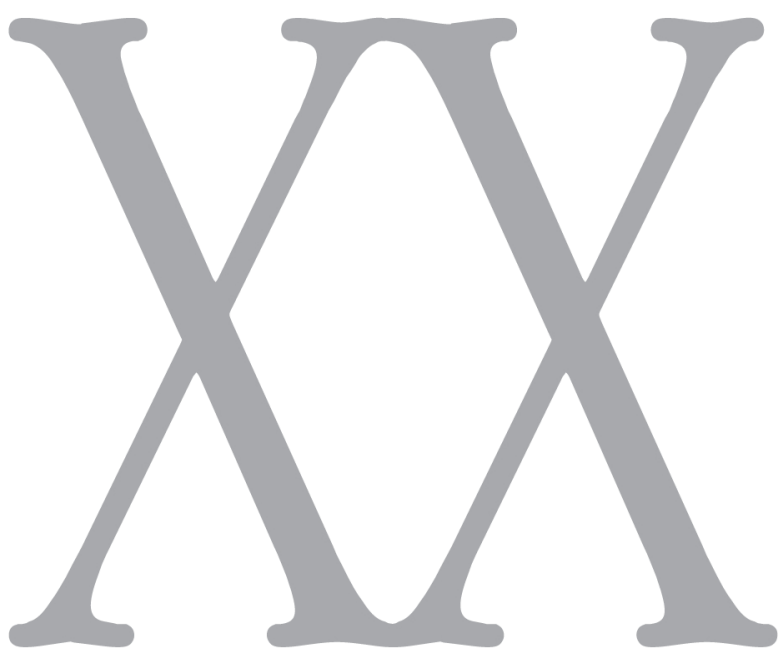

número $10 \cdot 2010$

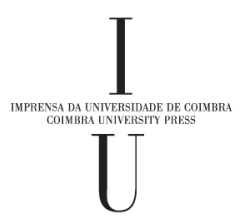


MARTINS, Rui Cunha - O Método da Fronteira. Radiografia Histórica de um Dispositivo Contemporâneo (Matrizes Ibéricas e Americanas). Coimbra: Almedina, 2008. 252 p. ISBN $\mathbf{9 7 8 9 7 2 4 0 3 4 5 4 6}$

Se tivéssemos que formular uma espécie de diagnóstico combinatório entre o inquérito frontal e a resposta imediata sobre a matéria analítica deste livro poderíamos resumir e condensar tudo na seguinte questão: $O$ que é a fronteira? Afirmativamente: Um dispositivo. Um método ordenador e configurador. Só assim estaremos em condiçôes de apreender a pertinência designativa que o próprio título da obra veicula, assim como a força que a construção teórica e hermenêutica posta em destaque nos interstícios das suas páginas revela na análise da problemática conceptual da fronteira. É precisamente no interior deste inquérito que o autor se instala no diagnóstico dos vários níveis problemáticos que desafiam o conceito de fronteira, tanto do ponto de vista da sua "operatividade» como também das «sucessivas incorporaçôes» que póem em causa a própria noção de fixidez do conceito: daí que a ilusão da ideia de fixidez do conceito de fronteira provocada pela alucinação dogmática da severidade do traço é desmentida pelas adaptações e incorporaçóes graduais e permanentes inerentes à própria historicidade que valida a condição de dispositivo da fronteira.

Todo o dispositivo funciona em articulação com um método intrínseco às funcionalidades múltiplas (sociais, políticas, culturais, identitárias, económicas, etc.) que lhe são demandadas a cumprir. Sendo assim, a opção analítica pela assunção clara da ideia de método ("princípio orientador») e de dispositivo (instrumento imbuído de uma "plas- ticidade» e passível de "articulação» e «negociação») intrínseco ao conceito de fronteira pode ser identificada nas diversas enunciações presentes no corpo do texto e que sub-repticiamente remetem o leitor para a pertinência da noção de método [e] da fronteira: "mecanismo ordenador» (p. 111.); "dispositivo viabilizador de estratégias de reprodutibilidade» (p. 168.); "objecto funcional de manejo», "objecto de celebração" e "razão instituinte de uma coerência» (p. 190.); "mecanismo demarcatório» (p. 229.). Para além do carácter epistémico que estas noçóes ganham no interior da moldura argumentativa construída pelo autor, em rigor, elas também acabam por reflectir o carácter dinâmico (entenda-se, de movimento) veiculado pelos diferentes regimes de temporalidades e de actuaçóes, manifestas nas duas principais categorias analíticas - «adaptabilidade» e «reprodutibilidade» - em torno das quais o livro constrói de forma transversal todo o debate sobre a problemática da demarcação (dimensão funcional da fronteira) e das "propriedades e funçóes» historicamente incorporadas no conceito. Aliás, a própria definição de fronteira que o autor esboça de forma propedêutica e telegráfica no primeiro ponto do primeiro capítulo do livro é manifestamente sintomática de duas revelações a considerar: primeira, a recusa de um certo totalitarismo da noção de fronteira (por esta se revelar como «tentativa - nunca totalmente conseguida de sinalizar uma sede ordenadora e produtora de sentido") em benefício das possibilidades emancipatórias que ela anuncia na sua "tarefa continuada da respectiva elucidação» (p. 23.); segunda, a prudência teórica que a própria definição transporta ao revelar a possibilidade sempre em aberto de adaptação e de reprodução convocada pela dialéctica do «limite» e da «ilimitação» enquanto 
debate que trespassa invariavelmente toda a matéria analítica do livro.

Da estruturação da obra, duas consideraçóes se impóem: a primeira prende-se com a opçáo designativa das duas partes que orientam a organizaçáo do livro Modelo. Dispositivo - a partir dos quais o autor, nos capítulos e subcapítulos subsequentes, exuma diferentes contextos e quadros históricos que permitem explicitar o regime problemático e o quadro genealógico da "passagem» da fronteira do "estatuto de modelo» a de "dispositivo»; a segunda, relaciona-se com a combinatória entre a matéria histórica e os desafios contemporâneos da fronteira na desmontagem de alguns dos mitos que alojaram no discurso pós-moderno sobre a fronteira, anunciando a sua obsolescência, o seu fim, a sua morte e pretendendo, consequentemente, remetê-la para uma espécie de silêncio sepulcral. Aliás, entre os sete tópicos (quatro na articulação do primeiro capítulo - Modelo - e três na análise do segundo - Dispositivo) que orientam a estruturação das duas partes do livro, pode-se sempre identificar o olhar crítico sobre a necessidade de recusa das enunciaçôes fúnebres da falência da fronteira em detrimento de uma abordagem que, através da mobilização dos exemplos históricos, solicita a construção de uma perspectiva onde é destacada a valorização do elemento funcional da fronteira e o consequente reconhecimento das suas dimensóes operativas e pragmáticas. Esta asserção é válida no quadro argumentativo apresentado no primeiro capítulo do livro (pp. 23-39) sobre os vários contextos e espaços de construção da «referencialidade fronteiriça» desenvolvida em articulação com outras "escalas identitárias»: aqui, o texto resgata-nos dos essencialismos associados à ideia de obrigatoriedade de uma oposição sempre frontal e contraditória quando diferentes referencialidades e escalas identitárias estão em presença, em detrimento de uma proposta de abordagem que privilegia a identificação das diferentes escalas e as "formas de relacionamento entre elas", tal como ficou asseverado na análise do estudo sobre a raia da fronteira hispano-portuguesa dos inícios da modernidade ibérica (pp. 31-37.). Outrossim, se o processo de construção de referencialidades se constitui também como um sistema de fundação e de tentativa de legitimação de pertença, então, qualquer acto de fundaçáo se alimenta de uma narrativa que, por sua vez, é também o suporte de uma memória constantemente celebrada, comemorada e rememorada (mediante a selecção dos motivos da recordação) como estratégia de fazer cumprir as funcionalidades subjacentes à atribuição de um sentido identitário e memorial à própria pertença (Cap. 2.): neste contexto, a fronteira é apresentada como um «referencial ordenador da memória» (p. 50.), tanto pela sua dimensão fundacional veiculada pelo "traço» e pela agregação das diferentes temporalidades numa "narração» que lhe confere sentido, memória e "delimitação», como também no estabelecimento gradual de "marcos divisórios» e de «lugares», através dos quais os indivíduos são convocados a se reconhecerem inseridos numa mesma «lógica delimitadora», também ela caracterizada por uma "narratividade» que acumula e transporta consigo a memória dos diferentes «momentos demarcatórios». Assim, da fronteira como «referencial ordenador da memória» subjazia também o «ideal da consolidação interna» no quadro espacial peninsular ibérico e, subsequentemente, o ideal expansivo expectável no horizonte africano (pp. 41-84.). É precisamente no interior dos actos ou dos momentos demarcatórios que 
o terceiro capítulo do Método da Fronteira se posiciona na revelação da dialéctica permanente da acção de delimitação: o limite (que evidencia o marco, o "lugar») e as suas acçóes de "desdobramento" e de "transgressão" no sentido da ilimitação, e esta como "expressão» daquele. Por isso, não existe ilimitação sem a figura do limite e a existência deste é condição apriorística de convite à ilimitação, cuja expressão, segundo o autor, parece convir às «formulaçóes originárias da teoria da soberania» (pp. 85-109.). Numa espécie de antecipação da segunda parte do livro dedicada à análise da fronteira como dispositivo contemporâneo, o quarto e último capítulo da primeira parte ensaia uma espécie de diagnóstico em torno da identificação das "teses matriciais do modelo moderno de fronteira» (Designação; Fundamento; e Disponibilidade), da qual a contemporaneidade é tributária. É como se a validação da fronteira enquanto dispositivo tivesse que ser antecipadamente corroborada pelas "dotaçôes funcionais» que viriam a ganhar estatuto de parte integrante do reportório matricial contemporâneo da fronteira (pp. 111-122).

$\mathrm{Na}$ segunda parte da obra (Caps. 5 e 6), a temática do dispositivo serve de fundo orientador para a organização do debate sobre a condição contemporânea da fronteira. Esta é analisada fundamentalmente a partir dos regimes relacionais que a contemporaneidade reclama: Adaptabilidade e Reprodutibilidade. O primeiro regime, por referência à capacidade/disponibilidade de ajustamento de novas funções - «novos modos de funcionalidade» - que a fronteira revela perante as demandas que cada contexto histórico lhe contesta. Tal é evidente nos exemplos das matrizes americanas analisadas, primeiro, à luz dos postulados de Frederick. J. de Turner sobre a frontier americana (pp. 129-135) e, segundo, à escala brasileira sobre o «lugar funcional...ocupado pela miscigenaçáo na órbita dos mecanismos fronteiriços» (pp. 135-152.). O segundo (Reprodutibilidade), por referência ao «desdobramento» que as fronteiras internas conhecem no processo prolongado pelas fronteiras externas; $\mathrm{Ou}$ seja, é como se a partir de uma matriz fronteiriça "original" - fronteira interna - se reproduzissem, em outras escalas, as referências que prolongam e reinventam a matriz original da fronteira interna, mas, numa dimensão regional ou local fronteira externa - tal como ficou patente nas intercessões das escalas de identificação regional, nacional e imperial, insufladas pelo nacionalismo salazarista do Estado Novo (pp. 153-191.). Contudo, é no interior do reportório das funcionalidades adquiridas pela fronteira que o último capítulo do livro (pp. 193-231) diagnostica alguns dos desafios contemporâneos enfrentados pelo dispositivo fronteira como o da "historicidade ou do contexto" (chamando a atenção para a necessidade de perscrutação dos quadros situacionais quando se avalia a configuração adoptada pela fronteira); o da "pós-estatalidade ou da articulação" (tendo em conta a necessidade cada vez maior do estado lidar com os novos desafios fronteiriços que reclamam «regulação» no interior das fronteiras da própria nação onde opera o estado); o da "democraticidade ou da demarcação", (por referência à dimensão plural das funcionalidades que a fronteira transporta, deve-se, sempre que possível, adicionar e investir um certo sentido democrático aos processos negociais de demarcação). Por isso, "o exercício democrático é a boa decisão, tanto como o convite à boa negociação" (p. 231.).

Em jeito de nota genérica, duas consideraçôes se impóem. A primeira prende-se com a forma como o autor, através de 
uma espécie de arqueologia das ideias, faz recorrência à matéria histórica enquanto suplemento factual para resgatar perspectivas que náo tinham sido consideradas no interior do debate historiográfico, imprimindo-lhes outros olhares à escala da problemática da fronteira. A segunda, complementar da primeira, inscreve-se na modalidade argumentativa posta em destaque ao longo da discussão. Não se trata exclusivamente da forma como a moldura argumentativa do título em discussão valida os pontos de vista realçados. Trata-se também da forma como o objecto em análise suscita a construção da teoria e esta, por sua vez, convida à própria leitura.

Victor Barros

Bolseiro de Doutoramento da Fundação Calouste Gulbenkian/CEIS20

ROSAS, Fernando; ROLLO, Maria Fernanda (coord.) - História da Primeira República Portuguesa. Lisboa: Tinta da China, 2009. 614 p. ISBN 978-972$-8955-98-4$

Em Junho de 2009 foi publicado, pelas Ediçôes Tinta da China, o livro coordenado por Fernando Rosas e Maria Fernanda Rollo, História da Primeira República Portuguesa. Trata-se de uma obra com a colaboração de especialistas das mais diversas áreas da investigação histórica, que colige, em seiscentas e catorze páginas, contributos para um conhecimento mais aprofundado da Primeira República Portuguesa.

O lançamento desta obra antecedeu em cerca de seis meses o ano em que se assinala o centenário da Primeira República Portuguesa, que propiciará, por certo, a multiplicação dos espaços de debate e de reflexão em torno desta temática. Esta obra pretende ser «mais uma acha para a fogueira» (p. 12).

A 5 de Outubro de 2010 comemora-se o primeiro centenário da Implantação da República. Trata-se de uma data muito relevante da História de Portugal - e extremamente inovadora na Europa - porque a República Portuguesa foi a terceira República Europeia, depois da Francesa e da Suíça.

No início do século XX a regra eram os impérios e as monarquias, com a excepção das Américas, nomeadamente a do Norte, que foi a República que serviu de exemplo a todas as outras ibero-americanas. A Primeira República Portuguesa constituiu uma das primeiras tentativas persistentes de estabelecer e manter uma democracia parlamentar.

Não obstante, apesar das intençóes e dos ideais generosos e do entusiasmo inicial, os republicanos foram incapazes de criar um sistema estável e plenamente progressista. A República foi prejudicada pela frequente violência pública, pela instabilidade política, pela falta de continuidade administrativa e pela impotência governamental. Com um total de quarenta e cinco governos, oito eleiçóes gerais e oito presidentes em quinze anos e oito meses, a República Portuguesa foi o regime parlamentar mais instável da Europa Ocidental.

$\mathrm{Na}$ «arena da República», as paixóes pessoais e ideológicas entrechocaram-se, tendo desencadeado forças que prepararam o terreno para a intervenção dos militares na política e para a instauração da ditadura. A esta República atribulada seguiu-se a ditadura militar, prólogo do «Estado Novo» que, no momento do seu 